\title{
KRONIK
}

\section{Tatilsiz Siyaset}

Dr. Onur Karahanoğulları, A.Ü. Siyasal Bilgiler Fakültesi

Yaz, tatil dönemidir. Çalışma zorunluluğundan kısa bir süre de olsa kurtulan insanlar, işyerlerini bu şansa sahip olmayanlara terk ederek memleketlerine, tatil yörelerine veya evlerine/mahallelerine çekilirler. Çalışma ve üretim yaz tatilinde de sürer elbette, ancak tüm ülke adeta rölantiye geçer. Televizyonlar "ciddi programları"n rafa kaldırır- gazeteler yaz tavsiyeleriyle dolar. Siyaset en az düşünülenidir; siyaset erbabı da bir olağanüstülük yaşanmadan rutin işlerle idare edip "büyük dönüşe" hazırlanmayı tercih eder. Okullarda yaz tatilini başlatan karne heyecanun muadili siyaset için Meclisin Haziran sonunda çalışmaya ara vermesidir. Eylül ile birlikte büyük dönüş başlar. Okulların açlmasıyla simgeleşen büyük dönüşte, toplumsal yaşam rölanti durumundan çikar. Meclis açılır, siyaset işlemeye, siyaset erbabı da heyecanlı tartışmalara girmeye başlar.

Elbette, sanayileşmiş Batilı toplumlar için geçerli olan bu tatil lüksünü Türkiye'nin yaşaması beklenemezdi. Türkiye, birkaç yıldan beri bu "tatil keyfini" yaşayamuyor. Doğal ve siyasal afetlere; deprem ve açlık grevlerine sahne olan geçen yılların yazlarından sonra bu yıl da tatili "kriz" içinde geçirdik. Tarihimizin en ilginç, ülkenin geleceği için kaygılanmayı biran için bir kenara bırakırsak, izlemesi en keyifli siyasal menevralarına tanık olduk. Tatilsiz, yedi gün/yirmi dört saat mesai yapan Türk siyasetinin bu özelliği sayesinde, Türk insanı tatil sonrası dönüş sendromu yaşamak külfetinden de kurtulmuş oldu.

Siyasetin yaz tatili 28 Haziran'da, Türkiye Büyük Millet Meclisinin 1 Ekim'de toplanmak üzere tatile girmesiyle başlamışt. Ancak, ülkeyi, yaz tatilinde siyasetten başka uğraşacak şeyler bulma yükünden kurtaran gelişmeler bu tarihten bir ay kadar önceye uzanyordu. Aşağıda, okuyucuyu sıkmayı göze alarak, Mayıs ortasında Başkaban Bülent. Ecevit'in hastalanmasıyla başlayan olaylar zincirini tarihlerle özetlemeye çalışacağız.

Başbakan Ecevit'in Mayıs ortasında hastaneye kaldırılmasıyla, "hastalık merkezli siyasal kriz arayışları" da başladı. Başbakan Yardımcısı Devlet Bahçeli, ilk kez 21 Mayıs'ta, Ecevit'in sağlığını bahane ederek hükümet hakkında spekülasyon yapılmasını eleştirdi ve Ecevit'in uygun gördüğü sürece başbakanıı̆̆1 sürdüreceğini belirtti. Hastalık merkezli siyasal kriz arayışının bundan sonraki seyri Ecevit'in hastaneye giriş çıkşlarının takibiyle, evinin önünde beklemelerle, Rahşan Ecevit'in eşine bakıp bakmadığının tartışılmasıyla 
geçti. Bunlar sadece magazin merakının malzemeleri değil, Türkiye'nin siyasal krizini oluşturan unsurlardi.

Başbakan Ecevit, 11 gün hastanede kaldıktan sonra, iyi olduğunu açıklayarak 28 Mayıs 2002'de görevinin başına "evine" döndü. 30 Mayıs'ta Dünya Bankası eski uzmanı, ekonomiden sorumlu Devlet Bakanı Kemal Derviş, erken seçimin Türkiye için "felaket olarak değerlendirilmemesi gerektiği" açıklamasını yaptı. 0 an için bu açıklamadan kalkarak olası gelişmeleri öngörmek ancak komplo teorileri ile mümkün olabilirdi.

Içeride, siyasal istikrarsızlık ve hatta kriz saptamaları yapılmasına karşılık, 4 Haziran'da, Amerika Birleşik Devletleri Dışişleri Bakanlığı sözcüsü Phil Reeker, Ecevit'in sağlık sorunlarının istikrarsızlık yaratmadığını açıladı. Haziran ayı, Ecevit'in ORAN istirahatı ve Rahşan Ecevit'in, DSP milletvekillerinin acil şifalar dileklerini kabulüne sahne oldu.

"Kriz günleri"nde siyaset yapmak zordur; siyasal sorunlarda siyasal tavirlar almak büyük sorunlar yaratır; günah keçisi ilan edilip çöle salınmanı, dışlanmanız an meselesidir. İdam cezasının kaldırılması konusundaki MHP'nin siyaseti, kriz yaratmamak adına etkisizleştirildi. Hastalıktan mütevellit siyasal krizin fonunda, "AB treninin kaçırılmayacağı" teması biteviye çalınmaktaydı.

Haziran ayı Kıbrıs konusunda önemli gelişmelerin yaşandığı bir ay oldu. Bölünmüş Kıbrıs'ın, Avrupa Birliği'ne üyeliği düşünülmeye; Rauf Denktas üzerinde $A B$ ve $A B D$ baskısı artırılmaya başlandı. Hükümet sözcüsü Sükrü Sina Gürel 18 Haziran'da, Kıbrıs'ın Avrupa Birliği'ne üyeliğinin Türkiye'nin üyeliğine bağlı olduğunu açıkladı. Ayın 19'unda Ecevit hâlâ evinde istirahattaydı. Dıșişleri Bakan İsmail Cem, Ecevit'e dış politika brifingi verdi. Rauf Denktaş - Glafkos Klerides, ayın 25'inde adada Belçika modelinin çözüm için zemin olabileceğini açıkladı. 27 Haziran'da Rum basınının Klerides'in Denktaş'a Türk tarafı için adanın 1/4'ünü önerdiği haberi yer aldı.

19 Haziran'da Bankacilı Denetleme ve Düzenleme Kurulu (BDDK) Pamukbank'a el koyarak bankacilık operasyonunu sürdürüyordu. Türk Sanayici ve İ Adamları Derneği (TÜSİAD) ekonomik belirsizlikten söz etmeye başladı. 21 Haziran tarihli gazetelerde Kemal Derviş'in ekonomik programın başarıla sürdürüldüğü açıklaması okunuyordu. Hastalık menşeli krizin en ilginç özelliği de bu oldu. Tüm istikrarsızlık ve kriz saptamalarına karşılık, Uluslararası Para Fonunun (IMF) Türkiye istikrar programınun gidişatında herhangi bir sorun yaşanmadı. Kriz ve istikrarsızlık manşetlerinin altında hep ekonomik programın iyi gittiği açılamaları yer aldı.

Başbakan Ecevit'in hastalanmasından yaklaşık bir buçuk ay sonra, 26 Haziran'da Partisi içinde bir hareketlenme yaşandı ve dokuz DSP'li milletvekili Ecevitin görevini bırakmasını istedi. Ecevit, kapsamlı bir sağlık kontrolünden sonra, birkaç hafta içinde görevinin başına dönebileceğini söyledi. 
28 Haziran'da, Başbakanın hastalığını temel alan siyasal belirsizlik saptamalarının yapıldığı, yeni boyut kazanan Kıbrıs görüşmelerinin hızlandığı, ABD'nin Irak'a savaş açma planlarının kuvveden fiile geçmek üzere olduğu bir dönemde TBMM, 1 Ekim'de toplanmak üzere tatile girdi.

\section{Siyasal belirsizlikten erken seçime}

Erken seçime varan süreçte, siyasal belirsizlik söyleminden siyasal istikrarsızlı̆a doğru yol alındı. Medyayı bir kenara bırakıp biraz daha dikkatlice baktı̆ımızda, Türkiye için siyasal kriz içinde bir ülke saptamasını yapmak pek de mümkün değildi. Aşağıda da göreceğimiz gibi, gerekli siyasal iradeyi üretmek bakımından hiçbir sorun yaşanmadı. İdam cezasının kaldırılması, anadilde eğitim ve yayın gibi önemli değişiklikler getiren 3. Uyum Yasası bu istikrarsızlık tartı̧maları içinde çıkarıldı. Tüm bu yaz krizi boyunca, IMF'nin Türkiye'de uyguladığı ekonomi programında herhangi bir aksama yaşanmadı.

30 Temmuz 2002 tarihli son Niyet Mektubu Türkiye'nin, maliye politikası, kamu borç yönetimi, para ve gelirler politikaları, bankacılık reformu, şirket borçlarının yeniden yapılandırılması, kamu sektörü reformu ve özel sektörün rolünün artrilması alanlarındaki taahhütlerini yerine getirme konusunda ne derece azimli olduğunu ortaya koydu. Ayrica, tüm bu süreç boyunca, iş çevrelerinden, IMF'den ve ABD'den yapılan ekonomik programinın yolunda gittiğine ilişkin açiklamalar eksik olmadi.

Meclis artık tatildeydi, ancak Türkiye'de siyasetin tatil yapmayacağı daha ilk günden belli oldu. 1 Temmuz'da Dünya Bankası Türkiye Yöneticisi Ajay Chibber, 'Türkiye'nin, Ekonomi Bakanı Kemal Derviş'in yönetiminde mütniş bir iktisat ekibine sahip olduğunu, ancak siyasal belirsizliğin ekonomiyi etkilediğini" açıklıyordu. Aynı gün gazetelerde, iş adamı Sakıp Sabancı'nın, Bülent Ecevit'in çekilmesi gerektiği, "Türkiye'nin genç ve enerjik liderlere ihtiyaç duyduğu" yolundaki açılaması yer alıyordu. Anamuhalefet partisi de erken seçim talebini yineliyordu. Koalisyon ortaklarının "2004'e kadar iktidarda olma" kararlılı̆̆ında henüz bir zayıflama görülmüyordu.

Anadilde eğitim ve idam cezasının kaldırılmasına ilişkin olarak, hükümet içinde yaşanan tartı̧malar siyasal belirsizlik kaygılarını artırsa da bundan önceki iki uyum paketini Meclis'ten geçirmeyi başaran hükümetin, bu konuda tartı̧ma yaşasa da, sonuca gideceği açıtı. O dönemde hükümetin küçük ortağı olan ANAP'in lideri Mesut Yılmaz, 3 Temmuz'da, TBMM'nin siyasal belirsizliği gidermek için Eylül'de olağanüstü toplanabileceğini açıkladı. 5 Temmuz'da Türkiye Odalar ve Borsalar Birliği (TOBB) koalisyon liderlerini, TÜSİAD da devlet bakan Kemal Derviş'i ziyaret ederek, Başbakan Ecevit'in sağlığından ve siyasal belirsizliğin olumsuz iktisadi sonuçlarından dert yandılar. 
8 Temmuz'da Devlet Bahçeli, Kasım'da erken seçim yapılması önerisini getirdi. Bu öneri ile, seçime gitmeden Ecevit'i çekilmeye zorlama ve yeni bir hükümet oluşturma arayışları da kadük hale geldi. MHP başkanı Devlet Bahçeli, hükümeti devirme yolundaki tüm girişimleri boşa çıaran önemli bir hamle yapmış oldu. Aynı gün Ecevit, televizyon kanallarından CNN Türk'e, olumlu gelişmeler yaşanırken hükümetin neden istifaya zorlandığını anlayamadığıı" açıkladı. Başbakanın bu "anlayamama" hali, kontrolü kaybettiğinin de göstergesiydi. 9 Temmuzda DSP'li 5 Bakan ve 19 milletvekili partisinden istifa etti. Aynı gün, ekonomiden sorumlu devlet bakanı Derviş, ekonomik programın iyi gittiğini ve bunun sürmesi için siyasal belirsizliğin uzamaması gerektiğini açıklıyordu. 10 Temmuz'da istifalar sürdü; partisiz kalan Derviş, DSP'den istifa eden Hüsamettin Özkan ve istifası beklenen İsmail Cem ile görüştü. İstifalar aralıklarla birkaç gün daha sürdü. Ancak Cem'in kopuşu, Derviş ile görüşmeleri sonucu biraz gecikmeli olarak ayın 12 'sinde gerçekleşti.

15 Temmuz'da yeni Dışişleri Bakanı Şükrü Sina Gürel, istifalar için (46 milletvekili) DSP'ye yönelik sabotaj nitelemesinde bulundu. 16 Temmuz'da eski Dışişleri Bakan, DSP müstefisi İsmail Cem, yeni bir parti kuracaklarını açıkladı. 18 Temmuz'da, Bakanlık görevini sürdüren Derviş, müstafi Cem ve Özkan ile yeni siyasal oluşumun liderleri olarak toplandı. DSP'den üç yeni istifa daha oldu.

Bu siyasal firtınanın ortasında 11 Temmuz'da, IMF Türkiye Masası Şefi Kahkonen, programin makroekonomik hedeflerinin iyi gittiğini, ancak siyasal belirsizliğin yabancı yatırımcıları endişelendirdiğini açıkladı. Siyasette, yaz ortasında can pazarı yaşanıyor, ısrarla siyasal belirsizlik ve yeni hükümet ihtiyacı saptaması yapıllyor, ama ekonomi hiç istifini bozmuyordu. Türkiye'de bir siyasal kriz değil, bir siyasal ameliyat yaşandı; ameliyat sirasmda beklenmedik gelişmeler görüldü, yeni ara hamlelere ihtiyaç dưyuldu, ama ameliyat başarıyla gerçekleşti. İhtiyaç duyulan ameliyatı gerçckleştiren de ekonomi çevrelerinin bildiği güvendiği bir operatör olunca, kriz tüm vaveylanın gerisinde, "mikroplu bir hastalık sirasında ortaya çıkan ve hemen her zaman iyileşmeye doğru gidişi haber veren ani ve yoğun değişiklik" olarak sevinçli bir telaş içinde mutlulukla karşılandı.

12 Temmuz'da Derviş, Ecevit ile görüşmesinden sonra istifa etti, ancak Cumhurbaşkanının devreye girmesiyle istifasını geri aldı. Görünüşte, istifa eden bir Devlet Bakanı idi; ama gerçekte, IMF programını yürüten kişinin istifası, hükümetin istifası gibi algılanabilirdi. Nitekim, TÜSİAD Başkanı, siyasal belirsizliği gidermek için seçimlerin yapılması gerektiğini belirtti.

16 Temmuz'da TBMM Başkanı Ömer Izgi, MHP'nin Türkiye Büyük Millet Meclisini 1 Eylül'de toplama çağrısını değerlendirmek üzere siyasi partilere çağrıda bulundu. 17 Temmuz'da, Koalisyon partilerinin başkanları 3 Kasım'da 
erken seçim yapılması konusunda anlaştılar. DSP'den altı yeni istifa ile birlikte Hükümet, Meclisteki çoğunluğunu kaybetti: Azınlık hükümeti. (Buna rağmen, aşağıda kısaca ele alacağımız Uyum Yasaları hükümet tasarısı olarak Meclis'ten geçirilebildi.) Kemal Derviş ekonomik programın sarsıntısız biçimde uygulandığını açıladı.

Devlet Bahçeli 3 Kasım seçimleri için ısrar etti. 23 Temmuz'da Bahçeli 3 Kasım için erken seçim kararı alınmazsa hükümetten çekiliriz dedi. Kahkonen, siyasal belirsizlik mali göstergeleri olumsuz etkilese de yürütülen iktisadi programın yolunda gittiğini açıkladi. 24 Temmuz, DYP ve MHP milletvekilleri Meclisi olağanüstü toplantıya çağırdı.

Ismail Cem ve Hüsamettin Özkan, Yeni Türkiye Partisini kurmaya karar verdi. 26 Temmuz, Devlet Bakanı Derviş Amerika gezisinde. Diplomatik kaynaklardan sizan bilgilere göre Derviş, Özkan ve Cem'e, dönüşte istifa ederek YTP'ye gireceği mesajını gönderdi. 30 Temmuz'da Ismail Cem, Kemal Derviş'in partisine katılacağı konusunda şüphesi olmadığını söyledi.

Meclis 31 Temmuz'da, erken seçimi görüşmek üzere toplandı. 449'a karşı 62 oyla, 3 Kasım erken seçim kararı alındı. DSP milletvekilleri aleyhte oy kullandı.

Derviş görevine devam edeceğini açıkladı.

29 Temmuz'da Mesut Yılmaz, Aralık ayının Avrupa Birliği için son şans olduğunu söyledi. 30 Temmuz'da TÜSİAD, Avrupa Birliği yasaları için tüm partilerin birlikte çalışmasını istedi. Seçim kararının hemen ardından 1 Eylül'de, 14 maddelik AB Uyum Yasaları görüşmeye başlandı. MHP dışında tüm partiler desteklerini açıkladilar. Siyasal iradenin üretilmesinde bir sorun yaşanmadı. Uyum paketinden, iş güvenliği yasa tasarısı ayrıldı (siyasal irade üretiminde bir sorun yok). Uyum yasaları kabul edildi. 5 Eylül'de TÜSİAD iş güvenliği yasasına karşı olduğunu açıkladı.

6 Eylül'de DSP, Emrehan Halıcı'ñn açıklamasıyla Derviş'in YTP üzerinden gerçekleştirdiği siyasal arayışların eleştirdi. Ardından Başbakan Ecevit, Derviş'in bir seçim yapması gerektiğini açıkladı. Ecevit'e göre, Derviş ekonomiden sorumlu bakan olarak iyi iş yapmıştı, ancak siyasetle ilgilenmesi işleri karıştırıyordu. Derviş, "ben zaten istifa etmiştim, geri aldırdınız" diye yanıt verdi. Ismail Cem, 9. Cumhurbaşkanı Süleyman Demirel ile görüştü. Tüm görüşmeler gibi bu da "faydalı" oldu. Bir gün sonra ise Demokrat Türkiye Partisi Başkanı olan, küçük Demirel Mehmet Ali Bayar ile görüştü. Seçimde ve seçim sonrası birlikte hareket etme kararı aldılar.

Kemal Derviş 10 Eylül'de görevinden ayrildı ve hemen ardından merkez-solu birleştirme görevini üstlendi. İsmail Cem, Hüsamettin Özkan ve Mehmet Ali Bayar ile görüştü. 14 Eylül'de solda birlik turları kapsamında, daha sonra aynı parti içinde yer alacakları Bayram Meral (o tarihte Türk-Iş Başkan) ile görüştü. 15 Eylül'de, Deniz Baykal, sola CHP çatısı altında birleşmeyi önerdi. 16 Eylül'de, 
Kemal Derviş, YTP'ye katılmaktan vazgeçti. Baykal'ın çağrısının önemli olduğunu açkladı. Ecevit, Derviş'in CHP ile çalışabileceğini açıklamasını şaşırtıc buldu. On gün sonra da DSP'ye yönelik bir komplo gerçekleştirildiğini, ancak bu komplonun arkasında kimin olduğunu hâlâ anlayamadığını belirtti.

20 Eylül'de JP Morgan Bankası, siyasal gelişmelere rağmen Türkiye'nin ekonomik programının iyi gittiğini, programın seçim sonrasında da devam ettirilmesi gerekliliğinin tüm partilerce benimsenmesinin olumlu olduğunu açıkladı.

23 Eylül'de, Kemal Dervis, CHIP merkez yürï̈tme kurulu ile görïistiii. Bu arada DSP'nin muhalif dokuzlarından altısı istifa etti. ANAP'tan da, Çalışma ve Sosyal Güvenlik Bakanı Yaşar Okuyan'dan sonra, Yücel Seçkiner ve 28 Eylül'de de Erkan Mumcu istifa etti. Okuyan MHP'ye, Mumcu AKP'ye katıldı.

10 Eylül'de son dönem Türk siyasetinin önemli bir özelliğinin açık bir örneğiyle karşılaştık. MHP, Avrupa Birliği Uyum Yasalarının iptali için Anayasa Mahkemesine başvurdu. Siyaset yapamayan siyasal aktörlerin, hukuku, siyasetlerinin tek aracı haline dönüştürmeleri kaçınılmaz. Türkiye'de siyaset uzun bir süreden beri, hukuk aracilığıyla ve hukuk üzerinden yapılıyor. Sonuç alınması son derece zor, kendisi de belli oranlarda siyasal değer yargılarıla hareket eden hukuksal hak arama yollarınin neredeyse siyasetin yegane arac haline gelmiş olması Türkiye'de siyasetin tükendiğinin de bir göstergesidir.

Erken seçim kararı alınmasından sonra, medyadaki "siyasi istikrarsızlık ve kriz" söylemi, bir anda ortadan kayboldu. Bu öcünün geri dönüşü, seçimi erteletme arayışlarının başlamasıyla görüldü. Hükümet ortağı ANAP'ın Genel Başkanı Mesut Yılmaz, 11 Eylül'de mevcut hükümetle seçime gidilemeyeceğini açikladı. DSP ve MHP buna karşı çıktı. 13 Eylül'de daha açık konuşan Yılmaz, seçimlerin, Avrupa Birliğinin Kopenhag zirvesinden sonraki bir tarihte, 15 Aralik'a ertelenmesini istedi. Kemal Derviş ise 18 Eylül'de seçimlerin ertelenmesinin ekonomiyi olumsuz etkileyeceğini, bu konudaki siyasi belirsizliğin giderilmesini istedi.

IMF de erken seçim yönünde destek verd: 20 Eylül'de, IMF yetkilisi Kohler, bu seçimlerin, iyi giden ekonomik programın bu şekilde sürdürülmesine katkı yapacağını umduğunu açıladı. Ay sonuna doğru seçimleri erteletme girişimleri başlatıldı. 23 Eylül'de, Başbakan Ecevit bu girişimleri eleştirdi. 26 Eylül'de, iş çevreleri seçimlerin zamanında yapılmasını istedi. 27 Eylül'de ise Dünya Bankası Başkanı, Türkiye ekonomisinin istikrarlı olduğunu açıkladı. Seçimlerin ertelenmesi girişimleri, TBMM'nin 1 Ekim toplantısında tatil kararı verilmesi ile sonuçsuz kald.

\section{Uyum yasaları}

Hastalıktan mütevellit siyasal krizin fonunda, "AB treninin kaçırılmayacağı" 
teması biteviye çalınmaktaydı. Uyum yasaları da bu temanın ürünü oldu. Kriz geçiren siyaset, Türkiye'nin önemli yasal değişikliklerini hayata geçirdi. Bir de bu "uyum yasalarına", IMF Türkiye programının gerektirdiği yasal ve yasa altı hukuksal düzenlemeler ve uygulamalar eklenirse, kriz geçirdiği saptaması yapılan siyasetin, "siyasal irade üretmek" bakımından hiç de sorunlu olmadiğ1 rahatlikla görülebilir.

2002 yılında üç adet Uyum Yayası çıkarıldı. Anayasa değişiklerine ve $A B$ gereklerine uymak için çıkarılan bu yasalardan sadece üçüncüsünü kısaca değerlendirmeye çalışacağız.

10.2.2002 tarihli Resmi Gazete'de yayımlanan 4744 sayılı ilk Yasa, Türk Ceza Kanunu, Terörle Mücadele Kanunu ve Ceza Muhakemeleri Usulü Kanununun bazı maddelerini değiştirmektedir.

9.4.2002 tarihli Resmi Gazete'de yayımlanan 4748 sayll ikinci Yasa ise, Basın Kanununun basılı eserlerin dağıtımının önlenmesi ve toplatılmasına ilişkin maddesi (hakim kararı veya gecikmesinde sakınca olan durumlarda savcı kararı); Devlet Memurları Kanunu (Avrupa Insan Hakları Mahkemesinin işkence nedeniyle hükmettiği tazminatların sorumlu personele rücu edilmesi); Siyasi Partiler Kanunu (parti kapatmanin yanısıra, Hazine yardımından yoksun bırakılma yaptırımı, kapatma usulüne ilişkin değişiklik ve "yasadışı faaliyetlerin odağı olma" kavramunın açıklanması); Dernekler Kanunu ve Toplantı ve Gösteri Yürüyüşleri Kanunu değiştirilmiştir.

3.8.2002 tarihli Resmi Gazete'de yayımlanan 4771 sayılı üçüncü Yasayla, öncekilere göre daha köklü değişiklikler öngörülmüştür. Siyasal belirsizlik, istikrarsızlık ve kriz saptamalanı yapıldığı bir dönemde, siyasal yaşamın önemli tarışmalarına yönelik düzenlemeler çıkarılabilmiştir. Ilk olarak, "savaş ve çok yakın savaş tehdidi hallerinde işlenmiş suçlar" için öngörülenler dışında idam cezası kaldırılmış; böylece, "Abdullah Öcalan'ın idamı" sorunu halledilmiştir.

Ikinci olarak Türk Ceza Kanuna, göçmen ve insan kaçakçılığı suçları eklenmiştir. Üçüncü olarak, Türkiye'de kurulan derneklerin yurtdışında faaliyette bulunmalan veya yurtdışında kurulmuş derneklerin Türkiye'de faaliyette bulunmaları, Bakanlar Kurulu'nun vereceği izinle olanaklı hale getirilmiştir. Aynı olanak vakıflara da tanınmıştır. Ayrıca derneklerin denetlenmesine, kaydına (Dernekler Kütüğü) ve takibine (Iç̧işleri Bakanlığ Dernekler Daire Başkanlığı) ilişkin ayrıntılı düzenlemeler getirilmiştir.

Dördüncü ve bir diğer düzenleme, Yasa çıktıktan sonra da hükümet içinde sorun yaratan, cemaat vakuflarının taşınmaz mal edinmesine izin verilmesine iliş̧indir.

Beşinci olarak, hukuk ve ceza davaları için, kesinleşmiş kararın Avrupa Insan Hakları Sözleşmesine aykırı biçimde verildiğinin, Avrupa İsan Hakları 
Mahkemesi tarafindan saptanmasi durumunda taninacak "yagılanmanin iadesi hakku" getirilmiştir.

Altıncı olarak, bir diğer önemli düzenleme de "Türk vatandaşlarınun günlük yaşamlarında geleneksel olarak kullandıkları dil ve lehçelerde yayın yapılabilmesi"nin kabul edilmesidir. Bunun yansıra bu dil ve lehçelerin öğrenimi hakkı da getirilmiştir.

Son olarak, Toplantı ve Gösteri Yürüyüşleri Kanununa eklenen bir düzenlemeyle yabancilara da toplantı ve gösteri yürüyüşü düzenleme hakkı tanunmiştır. Ayrica, Polis Vazife ve Salahiyet Kanununda yapılan değişiklikler ile polisin, üst arama ve yakalama yetkileri yeniden düzenlenmiştir.

Abdullah Öcalan'ın idam edilmemesi, ayrılıkçı hareketin talepleri arasında yer alan anadilde yayın ve eğitim talebinin kabul edilmesi, azınlık vakıflarına mal edinme hakkınin taninması ve Avrupa Insan Hakları Mahkemesi'nin kararlarının yargılamanın yenilenmesi sonucu doğurabilmesi. Tüm bunlar, milliyetçi bir partinin ortak olduğu Hükümetin tasarısı olarak Meclisten geçti. Türk siyasetinin, ilginç bir özelliğinin, iktidar partilerinin en azından görünürdeki ideolojik yönelimlerine taban tabana zit icraatlara imza atması özelliğinin bir tekrarını gördük. Alevilerden ve kentli aydınlardan oy alan SHP'nin Sivas katliamina engel olamaması ve Siyonistlerin bir numaralı muarızı Refah Partisi'nin Israil ile işbirliği anlaşmasını imzalaması benzer örnekler olarak düşünülebilir.

Uyum Yasalarının neler getirdiği, siyasal ve hukuksal sonuçların neler olabileceği ayrıntılı bir değerlendirmeye tabi tutulabilir. Özellikle, hukuksal ve demokratik olarak ileri olduğu savunulan düzenlemeler arasına "sıkışan" düzenlemeler (örneğin, 2. Uyum Yasası'nda yer alan, vali ve kaymakama toplantı yasaklama yetkisi veren düzenleme) tartışılabilir.

Yararlı olacak bu tartışmalarda şu gerçek gözden uzak tutulmamalıdır: Avrupa demokrasilerinin yasalarında da iderenin (devletin) gerektiğinde rahatça hareket etmesine olanak sağlayan, güvenlik, sağlık, kamu düzeni, gecikmesinde sakunca bulunma ve benzeri esnek kavramlar yer almaktadir. Baskıı yasalarımızı bir yana bırakarak, demokratik ölçütlere göre tanımlanan yasalar kullanulmaya başlansa bile, idarenin elini serbest burakan hukuki düzenlemelerin varlığı bir zorunluluktur. Devleti demokratik yapan, ona uygulanan ve onun uyguladığı yasaların belirli ölçütlere uyması olduğu kadar, iktidarınun, karşıt ve çeşitli toplumsal güç odaklarıyla dengelenmesidir. Etnik, sınufsal, kültürel, vb. her türlü toplumsal hareketi derhal etkisizleştiren bir devletin hukuksal yoldan demokratikleşebilmesi mümkün değildir. 


\section{Siyasette "yapısal" dönüşïm}

Mali krizin patlak vermesinden sonra, eski Dünya Bankası çalışanı, yeni Türkiye Cumhuriyeti Bakanı Kemal Derviş yönetiminde gerçekleştirilen krizden çıkış harekâtının, bir erken seçimle tamamlanacağı derhalde düşünülmemişti. Eski Dünya Bankası çalışanı, yeni Bakannın yönetimindeki harekâtın "iktisat" ile sınırlı kalacağı, IMF tarafından istenen ve Türkiye Cumhuriyetinin "zaten yapacağı" yapısal reformları gerçekleştirmenin yeterli olacağı düşünülmüştü. Ancak unutulan nokta, basitçe "yapısal reform" olarak geçiştirilen şeyin, aslında bir bütün olarak devlet örgütlenmesini ve devletin piyasa ile olan ilişkilerini kökten dönüştürdüğü; dönüşen kamu yapılanmasının ve kamu-piyasa ilişkisinin de yeni siyasal mekanizmalar ve hatta aktörler gerektireceği idi. Hukuken ayaklara dolanan özelleştirme ve tahkim sorunlarının yarattğı krizi çözmek için 1999 yılında Anayasa'yı değiştirecek gözüpekliği gösteren siyasal irade, aynı tavrını Derviş-IMF reformları için gerekli olan hukuksal yapıyı üretmek için de kullandı. Türkiye Cumhuriyeti tarihinin en yoğun yasama faaliyetinde bulundu. Bankacilik alanında, Türkiye Cumhuriyeti tarihinin en büyük devletleştirmesi gerçekleştirildi. Ancak bu denli iyi "iş gören" siyasetin kaderi, 2002 Yazında karşılaştı̆̆ı, siyasal istikrarsızlık teşhisi ve suçlaması belirledi.

Bu teşhisin gerisinde iki kısa dönemli, birisi ise uzun erimli yapısal üç ihtiyaç yer almaktaydı. kısa dönemli olanlar, esasen dış politika uzantılı ihtiyaçlardı. AB-Türkiye ilişkilerinde, Kıbrıs sorununa önerilen çözümler ve ABD'nin Kuzey Irak bölgesine ve Irak'a yönelik arayışlarında Türkiye'ye biçtiği rol, mevcut hükümete fazlasıyla ağır yükler yüklemektedir. Her türlü, IMF, AB ve Türkiye (büyük burjuvazisi) ihtiyaçlarıyla güdülenen yapısal düzenleme için irade üretmekten çekinmeyen hükümet için, Kıbrıs ve Kuzey Irak gerileyemeyeceği noktayı oluşturmaktadır.

Kriz teşhisinin gerisindeki yapısal ihtiyaca gelince: $\mathrm{IMF}, \mathrm{AB}$ ve Türkiye'nin belirlediği, Türk devletinin (genel olarak kamusunun) yeni yapılanmasının, ihtiyacı olan yeni siyasal yapılanmayı gerçekleştirme arayışıdır mevcut kriz söyleminin gerisinde yatan. Dönüşümün tüm yapısal reformlarını, yönünü, gereklerini ve yararını sorgulamadan gerçekleştirilen Türk siyaset erbabı, sıranın kendilerine geldiğini henüz fark edebilmiş değildir. Ekonominin siyasetten ayrilması, popülizmin siyasetten ayrılmasıdır. Popülizmin siyaseti terk etme gerekliliği mevcut siyasal aktörlerin pek çoğunun da sahneyi terk etmesini gerektirmektedir. 